\title{
Analysis of Primary School Music Teaching Plan Under the Multicultural Background
}

\author{
Jinyi Guo ${ }^{1 *}$ \\ ${ }^{1}$ Shaanxi Normal University, Xi'an, Shanxi 710119, China
${ }^{*}$ Corresponding author. Email: 2499951726@qq.com
}

\begin{abstract}
The phenomenon of multiculturalism has a long history. The current domestic research on multicultural teaching is mainly based on teaching theory and practice. The common feature is to study and explore the meaning of education from the perspective of multiculturalism. Primary education is the beginning of formal education for students, and is responsible for the task of cultivating students' learning ability. Music education is mainly to cultivate students' aesthetic ability and the ability to accept and learn other music cultures. Therefore, music teaching in primary schools should pay attention to the penetration of multiculturalism in the classroom, so that students can become more complete and comprehensive talents to adapt to the development of a diverse society. Based on the multicultural background, this article explores the teaching plan of primary school music, hoping to have certain guiding significance for improving the quality of primary school music teaching.
\end{abstract}

Keywords: Multiculturalism, primary school music, teaching

\section{INTRODUCTION}

The goal of music classroom teaching is that teachers will enable most students to achieve the expected learning results and standards through a series of music activities, which has a guiding role in music teaching activities. Since the formation and promotion of the concept of multiculturalism, the traditional music teaching model has been greatly influenced [1]. The traditional music teaching model can no longer meet the teaching standards of music courses. It is urgent to reform primary school music teaching to ensure that the multicultural music teaching concept is fully reflected in the teaching. Nowadays, multiculturalism has become an indispensable systematic theory in today's education field [2]. According to the current situation of domestic music teaching, teachers are undertaking arduous tasks and need to conduct long-term practical research in order to construct a multicultural music teaching system that is consistent with the national conditions. In recent years, more and more attention has been paid to the concept of multiculturalism, and this concept has also begun to penetrate in the process of developing music teaching activities, but it still has great shortcomings. This research is carried out to better guide primary and secondary school music. The development and implementation of teaching work promotes the development and progress of music education [3].

\section{MULTICULTURAL EDUCATION CONCEPT}

Multiculturalism refers to the general term for multiple cultures that exist in a society, country or nation. An important task of multicultural education is to make major reforms in school work, so that every student from multiple groups has an equal opportunity to succeed academically. Therefore, the educational quality of students of different genders, different nationalities and different cultures can be improved [4].

The ultimate goal of the school's multicultural education is to make society diverse and coexist, and to achieve human progress and development in the inheritance and selection of culture. Colorfulness is the source of a happy life. Society and educators must provide each student with the right and opportunity to choose cultural choices through education, so that they can acquire the knowledge and skills necessary to adapt to the ontological culture, non-ontological culture, and the global society, in order to establish an ideal society and educational diversity cultural environment. 


\section{PROBLEMS IN PRIMARY SCHOOL MUSIC TEACHING BASED ON MULTICULTURAL BACKGROUND}

\subsection{The teaching purpose is not prominent and the music classroom teaching is chaotic}

The teaching goals set by the school are mainly for teachers to clarify the teaching content, and they are aimed at the group of teachers, so as to restrain teachers' teaching activities. If classroom teaching is to be carried out in an orderly manner, it must be carried out around the purpose of teaching, otherwise there will be problems of low teaching efficiency [5].

When carrying out multicultural music teaching work, we must focus on comprehensive teaching, which can effectively integrate related art disciplines with music.

In the development of primary school music teaching, teachers should make full use of music materials, strengthen the relationship between music and other subjects, implement teaching activities around music aesthetics, enhance students' music aesthetics ability, and help students form correct personalities [6].

However, many teachers did not fully implement the teaching purpose of music when developing music courses, nor did they actively explore the relationship between music and other courses. The teaching goals are ambiguous, and the music courses carried out without the art synthesis will inevitably fail to achieve the desired effect. The knowledge and concepts of different subjects in the classroom may be used in music singing lessons. Many primary school students fail to really learn to sing; some teachers encourage students to participate, but they do not guide students to receive music essence.

Music curriculum is a comprehensive teaching based on music. It emphasizes comprehensive concepts and highlights diversity. Because music exists in a comprehensive environment, it may involve different aspects of education, art or culture.

\subsection{The promotion of national music culture lacks vitality}

Multicultural music education advocates the promotion of national music, and the new curriculum standard also regards the promotion of national music as a basic concept. The purpose is to enable students to understand and love the music culture of the motherland, and to enhance national consciousness and patriotism. However, it is understood that many students think that the folk music in the music class is not good, or that the teacher is very meaningless when teaching singing and enjoying such a class. This is mainly because teachers' teaching methods are relatively single and backward in teaching concepts. For example, when learning to sing or appreciating folk music, pure skill learning or listening makes students unable to appreciate the deep cultural connotation of folk music [8].

Some teachers simply think that multicultural education is the integration of culture, which means teaching students a lot of knowledge in the classroom, and achieve the purpose of music aesthetics through advanced teaching methods such as courseware teaching. Multicultural education in specific school teaching is to let students understand and learn how to face cultural diversity, to accept and appreciate the differences of different people. The focus is on cultivating students' multicultural adaptability and inspiring students to think independently and coordinate their attitudes. Multicultural education is to cultivate diverse abilities, not simply accumulation of knowledge. In music teaching, multicultural teaching should be based on the understanding and learning of musical elements.

\subsection{Single cultural content in teaching}

Judging from the classroom situation of primary school music teaching, many teachers do not pay attention to the cultural diversity of teaching materials. In particular, teachers'ability to control unfamiliar folk music is obviously weak, which is manifested in the unity of teaching content and teaching methods. For example, when teaching folk songs, they simply teach or introduce the songs. Let's look at national characteristics. Therefore, after the course technology, students can only feel whether the songs they learn in class are good, and cannot appreciate the songs in combination with national characteristics [7]. The weakening of the teaching material culture and the simplification of teaching activities have resulted in a lack of strong teaching culture atmosphere, which to a certain extent restricts the educational purpose of cultivating all-round development of people, and makes the inheritance of multiple music cultures superficial.

\subsection{Multicultural music is formed late, and students have little knowledge of it}

The formation of the concept of multicultural music teaching is relatively late, and there are still great differences in the understanding of its specific definitions and concepts. Therefore, many teachers have not fully understood the basic concepts, so they cannot accurately distinguish between multicultural and diversified music content. In the view of some teachers, the development of multicultural music teaching means combining teaching materials and explaining to students the national music, western music, and ethnic minority folk music. This is an essential error [9]. Teachers' ignorance of the concept of musical art diversity has become a key element that interferes with the realization of multicultural music 
teaching purposes. Understanding the cultural nature of music and being able to accommodate and appreciate differences in music culture is the basic pursuit of multicultural music teaching. Therefore, teachers should teach students based on the cultural background. The Han population is large. In elementary school music teaching, teachers and students subconsciously believe that learning Han music culture is necessary, but they lack the understanding and learning of other ethnic minority music cultures. If ethnic minority music is involved, it is only based on Han culture. Examining the culture of ethnic minorities from an angle, it fails to reflect the pluralistic characteristics of music culture. Different music art and culture have completely different expression themes. Even based on the same cultural field, the expression theme of each region will be different. Multicultural music teaching needs to be carried out, which can help students recognize the different cultural backgrounds. The various methods of musical expression, which are far from being achieved by learning singing alone.

\section{IMPLEMENTATION STRATEGY OF PRIMARY SCHOOL MUSIC TEACHING PROGRAM BASED ON MULTICULTURAL BACKGROUND}

\subsection{Combine a variety of teaching methods to teach students music}

In the process of developing elementary school music teaching activities, we must implement the multicultural teaching concept, realize the multicultural nature of teaching methods, and get rid of the drawbacks of traditional teaching methods [10]. Under the multicultural music teaching method, teachers should implement and develop from two levels of space and time. Among them, multicultural teaching at the time level requires teachers to extend the music classroom and make full use of the off-class time to carry out music teaching activities to help students put music learning into daily life to improve students' music appreciation ability. For example, students and parents can enjoy music at home, and enrich students' leisure life in the process of strengthening students' music learning; while multicultural teaching at the spatial level requires teachers to integrate music, formation background and development status. For example: organize students to clean up the surrounding environment, and collect related songs, so that students can get a more realistic learning experience in the process of practice. In addition, teachers should flexibly use a variety of teaching methods, give full play to the role of piano, electronic piano and accordion and other performance equipment, and use multimedia teaching methods to play musicals or concerts to make students' music classes more diverse.

\subsection{Increase the content of multicultural music courses}

Although the concept of multicultural music teaching has been embodied in the current music teaching materials, teachers rarely allow students to learn more knowledge of diverse music arts when carrying out teaching work. This has a lot to do with the lack of teaching evaluation mechanism. Music teachers mostly use geometry teaching experience to improvise teaching in the classroom, and rarely involve music knowledge they don't understand. As a result, students cannot learn diverse music knowledge at all, let alone compare and analyze different music culture.

When actually implementing multicultural music teaching, in order to improve teaching efficiency, teachers must appropriately and reasonably introduce multicultural music culture in combination with teaching content to make classroom content more substantial and rich. In the process of increasing the content of multicultural courses, teachers can select the characteristic culture and cultural essence of different nations in the world. These musical cultures have strong representatives of diversity. By explaining this knowledge, students' knowledge can be expanded and significantly enhancing students' cognitive ability and music skills is also of great help in cultivating students' musical emotions. For example, when teachers explain national folk music, they can add some world national music, ethnic music, etc. to the content of the curriculum, and infiltrate this knowledge in all aspects when teaching activities are carried out, so that the level of students' multiple musical senses can be significantly improved.

\subsection{Follow the basic method of multicultural music teaching}

Elementary school music teachers do not thoroughly understand the concept of multicultural music teaching is the key reason that affects the improvement of teaching efficiency, and many teachers are unable to scientifically use multicultural teaching methods to stop multicultural music teaching. Therefore, the main task at present is to clearly define the concept of multicultural music teaching. In essence, as a teaching concept, it can be regarded as a teaching paradigm. The paradigm refers to the viewpoint of the philosopher Kuhn, which in his view is the basic worldview formed by many scholars in this field for a certain discipline. There are essential differences with other music teaching value systems. The content of multicultural music teaching concepts covers teaching methods, teaching content and teaching goals.

The teaching methods that can be applied in the process of multicultural music teaching are mainly as follows: first, when conducting multicultural music teaching activities, it should be carried out based on the formation of music as a parent culture. Because of the 
cultural characteristics of music, it is necessary to strengthen the relationship between music and culture. In order to learn music more comprehensively and thoroughly, students cannot understand the connotation of music when they are separated from the cultural environment, which will inevitably affect the improvement of teaching efficiency; in addition, schools should also actively develop music practice activity. Because theory and practice are inseparable, in the process of learning multicultural music courses, teachers should guide students to participate in the practical activities of music learning when necessary, use practical activities to appreciate music, and learn music singing skills.

\subsection{Integrate elementary school curriculum to strengthen the connection with multicultural music}

Based on the original music education mechanism and influenced by previous teaching concepts, different disciplines are poorly connected and highly independent. However, in view of the current teaching and social development status, subject integration has become an inevitable development trend, so it is imperative to carry out multicultural music teaching. The fundamental goal of multicultural music teaching is to let students understand the essence of music culture, but in the process of practical teaching, not only must actively carry out music teaching, but also involve more knowledge points under music art. Teachers must weaken the gap between music and other courses and strengthen the connection between different disciplines, including art, history, and Chinese. Teachers of different disciplines should also communicate and exchange, and share teaching content. Make up for the only child, enrich the music teaching classroom, and significantly improve the teaching efficiency. Insufficient disciplines. Primary school music teachers should explain the content of Chinese poetry, traditional folk songs and historical knowledge.

\section{CONCLUSION}

Multiculturalism embodies a very unique aspect in elementary school music classrooms, so it is of great significance to study multiculturalism and effectively penetrate into music classrooms. For elementary school music education, it is the starting point for students' music journey, and it is also the best stage to meet students' spiritual needs and cultivate students' personal hobbies. In order to better enable students to develop in music, it is necessary to have a comprehensive understanding of music culture, and to edify the temperament of primary school students.

\section{REFERENCES}

[1] Wu, H. Y. (2020) Diversified Harmony and Music Classroom Students' Creativity Cultivation Research. Examination Questions and Research, 32:101-102.

[2] Kong, L. N. (2020) Let multiple cultures merge with each other in elementary school music classroom. Northern Music, 17:109-110.

[3] Shen, X. M. (2020) Thoughts on Diversified Evaluation of Primary School Music. New Curriculum Guide,23:74-75.

[4] Cai, L. J. (2020) Using diversified strategies to strengthen the effect of primary school music teaching. China Extra-School Education, 16:16-17.

[5] Lu, P. S. (2020) Thoughts on diversified strategies to improve the effectiveness of primary school music appreciation teaching. Examination Weekly,41:151152.

[6] Peng, N. (2020) Infiltrate Chinese traditional cultural education to improve the effect of primary school music teaching. Northern Music,04:216-217.

[7] Guo, X. Y. (2019) Analysis of the development of multicultural music education in elementary school music education. Chinese Journal of Education, S2:85-86+90.

[8] Li, W., Qiu, Y. W. (2019) A study of primary school music classroom based on core literacy. Art Education, 09:65-66.

[9] Cui, Y. (2019) The integration of multicultural music education in college music teaching. Northern Music, 39(14):157+160.

[10] Wei, L. G. (2019) Innovative exploration of the concept of primary school music education. New education, 13:64-65. 